\title{
REVIEW
}

\section{Best timing for energy provision during critical illness}

\begin{abstract}
Mette M Berger ${ }^{1 *}$ and Claude Pichard²
This article is one of eleven reviews selected from the Annual Update in Intensive Care and Emergency Medicine 2012 (Springer Verlag, DOI: 10.1007/978-3-642-25716-2) and co-published as a series in Critical Care. Other articles in the series can be found online at http://ccforum.com/series/annualupdate2012. Further information about the Annual Update in Intensive Care and Emergency Medicine is available from http://www.springer.com/series/8901.
\end{abstract}

\section{Introduction}

Malnutrition is a persistent problem in hospitals and intensive care units (ICUs) worldwide. Critically ill patients quickly develop malnutrition or aggravate a preexisting malnutrition because of the inflammatory response, metabolic stress and bed rest, which all cause catabolism $[1,2]$. The persistence of this problem despite existing guidelines, is partly explained by the absence of immediately visible consequences of acute malnutrition: Deleterious consequences are not easily measurable and become obvious only after 7-14 days, i.e., frequently after discharge from the ICU. Nevertheless, after a week already, new infections may be attributable to incipient malnutrition [3,4]. In contrast, the biological consequences of insufficient oxygen delivery are immediate, requiring the ICU team's rapid attention. This longer time constant between event and consequence is one of the important reasons why nutritional therapy is so frequently forgotten early on, resulting in progression of energy deficits, in turn associated with impaired outcome.

Confusion has arisen in recent years among ICU specialists because of the publication of conflicting results about the respective merits of hypo- and hypercaloric feeding [5]. Indeed, some studies suggest that feeding the critically ill patient is deleterious in terms of glycemic control and clinical outcome [6-8], whereas other trials confirm that acute malnutrition causes complications and increases mortality at levels of energy deficit that are current in clinical practice [2,3,9-11].

The principal issue appears to be the need to be able to prescribe within the first 24-48 hours an optimal and individualized energy and protein target, and to monitor achievement of this goal.

\footnotetext{
*Correspondence: Mette.Berger@chuv.ch

'Service of Intensive Care Medicine \& Burns, CHUV, Lausanne, Switzerland

Full list of author information is available at the end of the article
}

\section{How do we define nutritional requirements?}

Prediction of the optimal energy target is relatively difficult in critically ill patients because of the high variability in resting energy expenditure during the course of severe illness as a result of alterations induced by shock, sedation, fever, reduction of lean body mass, surgical procedures, etc. A reasonable prediction requires knowledge of the accurate pre-illness weight and body height, but this information is frequently missing. When an actual body weight is available, it is generally inaccurate as a result of fluid accumulation following resuscitation. The actual weight is also frequently increased by excess fat mass, which nobody wants to feed (Figure 1).

Guidelines recommend that energy expenditure be measured on an individual basis by indirect calorimetry. The underlying physiological principle is that calculation of energy expenditure from the measurement of oxygen consumption $\left(\mathrm{VO}_{2}\right)$ and carbon dioxide production $\left(\mathrm{VCO}_{2}\right)$ reflects the energy needs at the cellular level. The essential assumption is that under steady state conditions, respiratory gas exchange is in equilibrium with gas exchange within the mitochondria, thus indirectly measuring oxidative phosphorylation. Energy requirements are then extrapolated using the Weir equation [12]:

\section{Total energy $=3.9$ liters of $\mathrm{O}_{2}$ used + 1.1 liters $\mathrm{CO}_{2}$ produced}

The limitations and obstacles to measurements in clinical settings are those impeaching stable conditions: Change in vasoactive drugs, an inspired oxygen fraction $\left(\mathrm{FiO}_{2}\right)>60 \%$, fever with shivering, an abnormal $\mathrm{pH}, \mathrm{CO}_{2}$ retention, patient movement, leaks in the system, and the use of nitric oxide (NO) [13].

This technique is relatively time-consuming and expensive. Indirect calorimetry, despite being the gold standard 


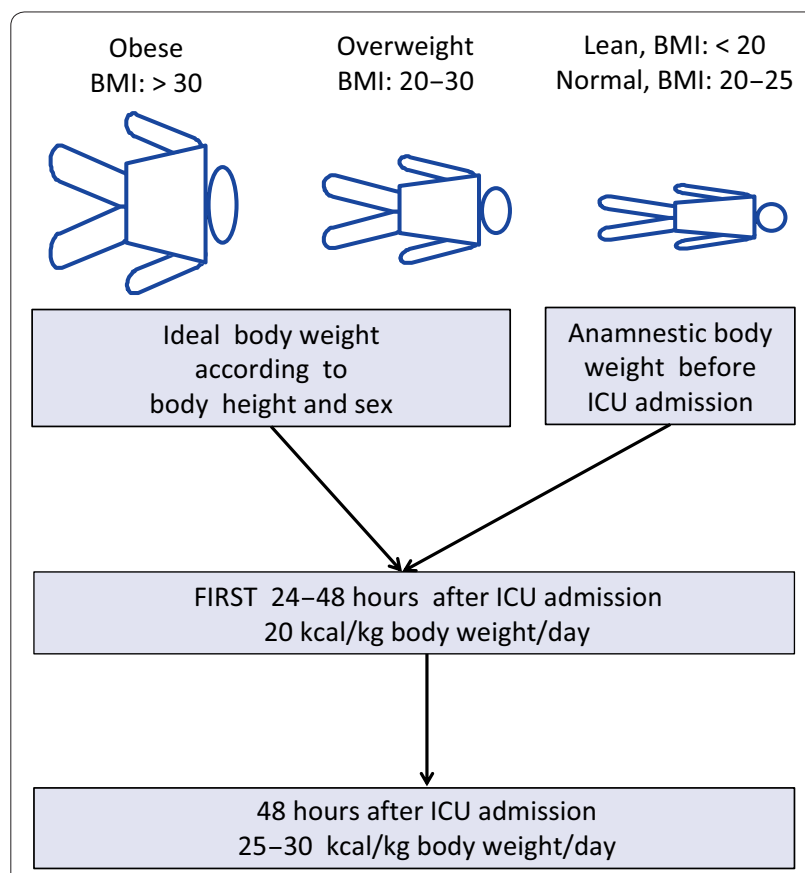

Figure 1. Actual body weight is usually artificially increased by the expansion of body water (i.e., fluid administration, stressrelated water retention). Therefore, it is recommended that energy requirements are calculated based on the anamnestic body weight for lean or normal weight patients (body mass index [BMI] = [body weight/ (body height) $\left.{ }^{2}\right]$ ) and the ideal body weight for overweight and obese patients $(\mathrm{BMI} \geq 20)$.

for determination of energy expenditure, remains unavailable in the vast majority of ICUs [14]. Inclusion of an indirect calorimeter in modern ventilators would represent a major technical advance. Another problem is that energy expenditure varies over time. Measurement at one time point can be very different from total 24-hour energy expenditure; the latter can be measured using the double-labeled water method [15-17]. This technique is based on the assumption that ingested double-labeled water $\left({ }^{2} \mathrm{H}_{2} \mathrm{O}\right.$ and $\left.\mathrm{H}_{2}^{18} \mathrm{O}\right)$ is distributed rapidly and homogeneously within the body water pool and more importantly that oxygen atoms in exhaled $\mathrm{CO}_{2}$ and water are in isotopic equilibrium. By giving a dose of $\mathrm{H}_{2}{ }^{18} \mathrm{O}$, both the water and $\mathrm{CO}_{2}$ pool will be labeled, whereas when ${ }^{2} \mathrm{H}_{2} \mathrm{O}$ is given, only the water pool will be labeled. Total energy expenditure measured by this technique is 1.4 times the energy expenditure measured by indirect calorimetry in critically ill in septic and trauma patients [15]. This method is only applicable in research settings.

\section{What should we do while waiting for clever 'metabolic' ventilators?}

The above technical problems, along with the limited availability of indirect calorimetry, have led to the development of predictive equations as surrogates, most of which have been shown to be inaccurate [18]. The Harris \& Benedict equation (adjusted or not for ideal body weight), and equations of Owen, Mifflin, the American College of Chest Physicians (ACCP), IretonJones 1992 and 1997, Penn State 1998 and 2003, and Swinamer 1990 are the most commonly used. These equations have all repeatedly been shown to be poorly correlated with the results of indirect calorimetry in critically ill patients $[16,18,19]$. Further, these equations are open to misinterpretation, as they often include a subjective 'stress factor' varying between 110 and $200 \%$.

Two equations have been developed for critically ill patients based on regression analysis of multiple variables collected during indirect calorimetry: The Toronto equation for major burns [20] and the Faisy-Fagon equation for patients on mechanical ventilation [21]. The latter equation calculates resting energy expenditure on the basis of body weight, height, minute ventilation, and body temperature and is clinically more accurate than the other predictive equations for metabolically stable, mechanically ventilated patients [21].

\section{Consequences of under- and over-feeding}

Both extremes of feeding have well defined adverse effects and should be avoided [22].

\section{Overfeeding: more is worse ...}

In the 1980s, the concept of parenteral hyperalimentation prevailed. This new therapy indeed saved multiple lives, but simultaneously caused serious complications. Further the concept of counting only non-protein calories, but not including the energy from proteins, contributed to overfeeding. This way to calculate energy intake should definitively be banned: All energy sources should be included in the total energy counts [23,24]. Finally, a computerized information system is needed to be aware of the rather important amounts of energy infused for non-nutritional purpose, including glucose $5 \%$ solutions and fat soluble sedatives [25]. Such inaccuracies have been responsible for systematic overfeeding in several studies.

Hypercaloric feeding has well known deleterious consequences on glycemic control, liver function, infections, and outcome. Detailed analysis of several papers supporting the negative effects of feeding $[6,26]$ show that the authors were actually overfeeding their isocaloric groups, with the expected deleterious clinical consequences, which invalidates the interpretation of the results. In a study including $200 \mathrm{ICU}$ patients receiving parenteral nutrition, Dissanaike et al. showed that increased parenteral caloric intake was an independent risk factor for blood stream infections [6]: Three groups out of four received more than $26 \mathrm{kcal} / \mathrm{kg}$ per day, with the mean energy intake in the group with blood stream infections being $35 \mathrm{kcal} / \mathrm{kg}$ ! This study should have been called the 'effects of overfeeding'. 
An important characteristic of ICU patients, is their poor tolerance to overfeeding. In a large multicenter study conducted in 40 Spanish ICUs and including 725 patients receiving either enteral or parenteral nutrition, Grau et al. showed that overfeeding ( $>27 \mathrm{kcal} / \mathrm{kg}$ ) was one of the determinants of altered hepatic function [22]. The problem started at values as low as $110-120 \%$ of true requirements, with early increases in the liver enzymes AST and ALT after 3-4 days, followed by increased cholestasis or a combination of both [22].

The consequence of this high liver susceptibility to overfeeding is that an accumulated energy deficit cannot be recovered by giving $120-130 \%$ of requirements for a few days. The 'gavage' causes hepatic steatosis, the 'foie gras' of geese. In cases of early insufficient energy delivery, the patients get a 'double hit': First by the complications of underfeeding, followed by those of overfeeding. The only strategy is, therefore, to prevent development of a relevant energy deficit by starting enteral feeding early.

\section{Underfeeding and pseudo-underfeeding}

In reaction to trials that showed the deleterious effects of overfeeding, a few investigators hypothesized that semistarvation might be the solution. Ahrens et al. randomized 40 surgical patients to receive either 'low-calorie' parenteral nutrition (20 non-protein $\mathrm{kcal} / \mathrm{kg} /$ day) or standard parenteral nutrition (30 non-protein $\mathrm{kcal} / \mathrm{kg} /$ day) [26]: To this, the investigators added lipid emulsions 3 times weekly, resulting in an additional $3 \times 1000=3000$ kcal for all patients. The authors concluded that the administration of 'low-calorie' parenteral nutrition resulted in fewer ( $0 \%$ versus $33 \%)$ and less-severe hyperglycemic events, with reduced insulin requirements. The problem is that all patients were overfed, the pseudo-lowcalorie group being less overfed than the other, so of course doing better! As previously stated, all substrates must be included in the calculations [24]!

After a study by Fong et al. in volunteers given endotoxin [27], parenteral nutrition became considered a poison, because its delivery had primed a stronger inflammatory response compared with enteral nutrition. Over the subsequent two decades, the pendulum shifted towards predominance of enteral feeding with the appearance of malnutrition. The earliest study to show worsening of outcome related to growing negative energy balances came from the UK and was conducted in 57 critically ill patients [28]: With targets set by calorimetry, the authors showed that a cumulated energy deficit above $-10000 \mathrm{kcal}$ was associated with increased mortality.

Negative energy balances and low feeding supply have since been shown to prevail across diagnostic categories $[2,10,29,30]$. Two prospective studies conducted in ICUs with feeding protocols and using indirect calorimetry and the same computerized information system customized for nutritional monitoring (Metavision, iMDsoft, Tel Aviv) [10,11] showed a proportionality between an increasing energy debt and clinical complications, particularly infection rates. Energy deficit developed in respectively $55 \%$ and $60 \%$ of the patients. The cut-off for increasing complication rates in both studies was between -4000 and $-8000 \mathrm{kcal}$ of cumulated energy balance corresponding to -50 to $-110 \mathrm{kcal} / \mathrm{kg}$. The same type of impact on infectious complications was observed in a neuro-ICU after subarachnoid hemorrhage in which the mean cumulative energy balance over the first 7 days was $-117 \mathrm{kcal} / \mathrm{kg}$ [31].

Rubinson et al. showed in 138 patients that the incidence of bacteremia was directly related to energy delivery with a steep increase in those patients receiving less than $25 \%$ of that recommended by the ACCP [3]: The difference appeared already by day 7 after admission. Using the same ACCP recommendations, another American study, including 187 medical ICU patients, showed that unintentional hypocaloric feeding occurred on $51 \%$ of ICU days [7]. A randomized British study including 277 patients and testing enteral immunonutrition ended up delivering a median intake of $14 \mathrm{kcal} / \mathrm{kg} / \mathrm{day}$ to both groups [32], which compromised the interpretation of their trial. In a French study, including 38 medical ICU consecutive adult patients intubated for at least 7 days on early exclusive enteral feeding, the patients with a mean energy deficit of $-1,200 \mathrm{kcal} /$ day had a higher ICU mortality rate than patients with lower deficit after two weeks $(p=0.01)$ [33]. The same authors showed recently that the level of energy deficit was also a determinant of the type of microbial agents causing the infectious complications, Staphylococcus aureus being predominant in ventilator-associated pneumonia in patients with the largest energy deficits [34]. This phenomenon is worldwide as shown by Alberda et al. in 2,772 mechanically ventilated patients [2]: The level of energy intake averaged $14 \mathrm{kcal} / \mathrm{kg} /$ day across countries with a mean delivery of $1,034 \mathrm{kcal} /$ day and $47 \mathrm{~g}$ protein/day. Of note, an increase of $1,000 \mathrm{kcal}$ per day was associated with a progressive mortality reduction.

Energy requirements are pathology dependent. It is, therefore, not surprising that the level of energy intake required to prevent problems is higher in patients with major burns as shown by a prospective Finnish study: The intake cut-off separating patients with and without nutrition-related complications was shown to be about $30 \mathrm{kcal} / \mathrm{kg} /$ day [35]; the lower delivery was associated with a $32.6 \%$ death rate versus a rate of $5.3 \%(\mathrm{p}<0.01)$ in those receiving adequate feeding; the pneumonia rate doubled, sepsis rate increased 1.8-fold $(\mathrm{p}<0.05)$, and the length of stay was prolonged by 12.6 days $(\mathrm{p}=0.01)$.

A recent ICU study from the Netherlands showed that protein delivery is another player in outcome because 
optimal intake further reduces mortality when the energy target is reached: Achievement of the guideline levels $(1.2 \mathrm{~g} / \mathrm{kg} /$ day $)$ should be monitored [36].

In summary, semi-starvation may possibly be tolerated in young patients who are not too severely ill, although nobody knows yet exactly how long fasting is tolerable in acute illness without deleterious consequences. Data in healthy subjects show that the duration is probably shorter than previously believed [37], with mitochondrial alterations already detectable after 18 hours. But current ICU populations are older and more severely ill than ever, and often stay for prolonged periods of time. Inappropriate feeding jeopardizes recovery. As long as we have no laboratory determinations available for clinical settings, the calculation of energy deficit probably constitutes a good surrogate for detection of complications: The cut-off for appearance of biological consequences of underfeeding is probably somewhere between -50 and $-60 \mathrm{kcal} / \mathrm{kg}$ body weight.

\section{Clinical evidence from intervention studies}

Optimizing energy delivery by individualizing and adapting it to a patient's daily status is a new concept [38]. Combined nutrition, with parenteral nutrition to top up insufficient enteral nutrition is a tool to prevent a growing energy deficit while using the gut. Several recent interventional trials are now delivering results.

\section{The TICACOS trial}

Recently, a prospective controlled randomized trial including 112 critically ill patients, tested the clinical impact of two strategies on outcome [39] while closely monitoring energy expenditure using indirect calorimetry. In the study group, energy target was adapted daily to these results (TIght CAlorie COntrol Study = TICACOS) whereas in the control group, the target was fixed at $25 \mathrm{kcal} / \mathrm{kg} / \mathrm{d}$. The authors observed a significant difference in energy delivery $(+600 \mathrm{kcal} /$ day $)$ and in protein delivery $(+13 \mathrm{~g} /$ day) between the groups, in favor of the calorimetry group. As a consequence, daily and cumulated energy balances were positive in the intervention group, versus negative in the control group. Unfortunately, non-nutritional energy was not taken into account for feeding prescription, which led to modest systematic overfeeding with prolonged mechanical ventilation and more infections. This tighter energy management was nevertheless associated with a significant reduction in post-ICU mortality. The study has weaknesses, but is the first to show that individualized nutritional support brings clinical benefit.

\section{The EPaNIC trial}

This large study, Early Parenteral Nutrition to supplement insufficient enteral nutrition in Intensive Care patients
(EPaNIC), randomized patients on admission to early (day 2) versus late (day 8) parenteral nutrition and concluded that early hypercaloric parenteral nutrition was deleterious [40]. This is no surprise, and confirmed what we have known for 20 years, since the Veterans' study published in the same journal [41].

This study has several limitations and was not at all in line with the European Society for Clinical Nutrition and Metabolism (ESPEN) guidelines [42], which the study claims to have followed for the early parenteral nutrition group. The patients of the early parenteral nutrition group did not have a clear indication for this technique. Patients were fed intravenously even though they had no clinical indication for this therapy because of a very short stay (39.1\% of the studied population had left the ICU by day 3 , and $>50 \%$ by day 5 ) or conditions that rarely need parenteral nutrition, such as elective heart surgery $(61 \%$ of the population). Large and numerous studies have shown the advantage of the enteral route over the intravenous route in ICU patients. This misinterpretation raises an ethical question as the guidelines state that no parenteral nutrition should be initiated unless enteral nutrition has been tested.

Energy delivery was elevated early on during the most acute phase of illness, with the delivery of glucose $20 \%$ to the parenteral nutrition group. Further there was no confirmation of the energy targets by indirect calorimetry. Early elevated intravenous energy delivery has been shown to result in increased morbidity. The study certainly included patients who merited parenteral nutrition but these were hidden by the forest of patients without an indication. Patients with severe malnutrition (body mass index $[\mathrm{BMI}]<18.5$ ), who may have benefited from parenteral nutrition, were excluded. This study confirms that parenteral nutrition should not be considered on admission.

\section{The SPN trial}

The latest study to investigate timing of feeding is the Supplemental Parenteral Nutrition (SPN) trial [43]. This Swiss bi-center, randomized trial enrolled 305 patients who stayed for at least 5 days in the ICU in whom enteral nutrition was initiated but clearly insufficient $(<60 \%$ of energy target on day 3). Supplemental parenteral nutrition was delivered to cover $100 \%$ of target, measured mostly by indirect calorimetry, from day 4 to day 8 , whereas enteral feeding was pursued in all patients, in line with ESPEN guidelines (indication for parenteral nutrition was enteral nutrition failure) [42]. The authors applied a glucose control strategy (target $<8 \mathrm{mmol} / \mathrm{l}$ ), and glucose control was not compromised by the supplementary parenteral nutrition [44]. Isoenergetic feeding improved outcome, with a significant reduction in new infections, an increase in antibiotic free days, and reduced time on mechanical ventilation. 


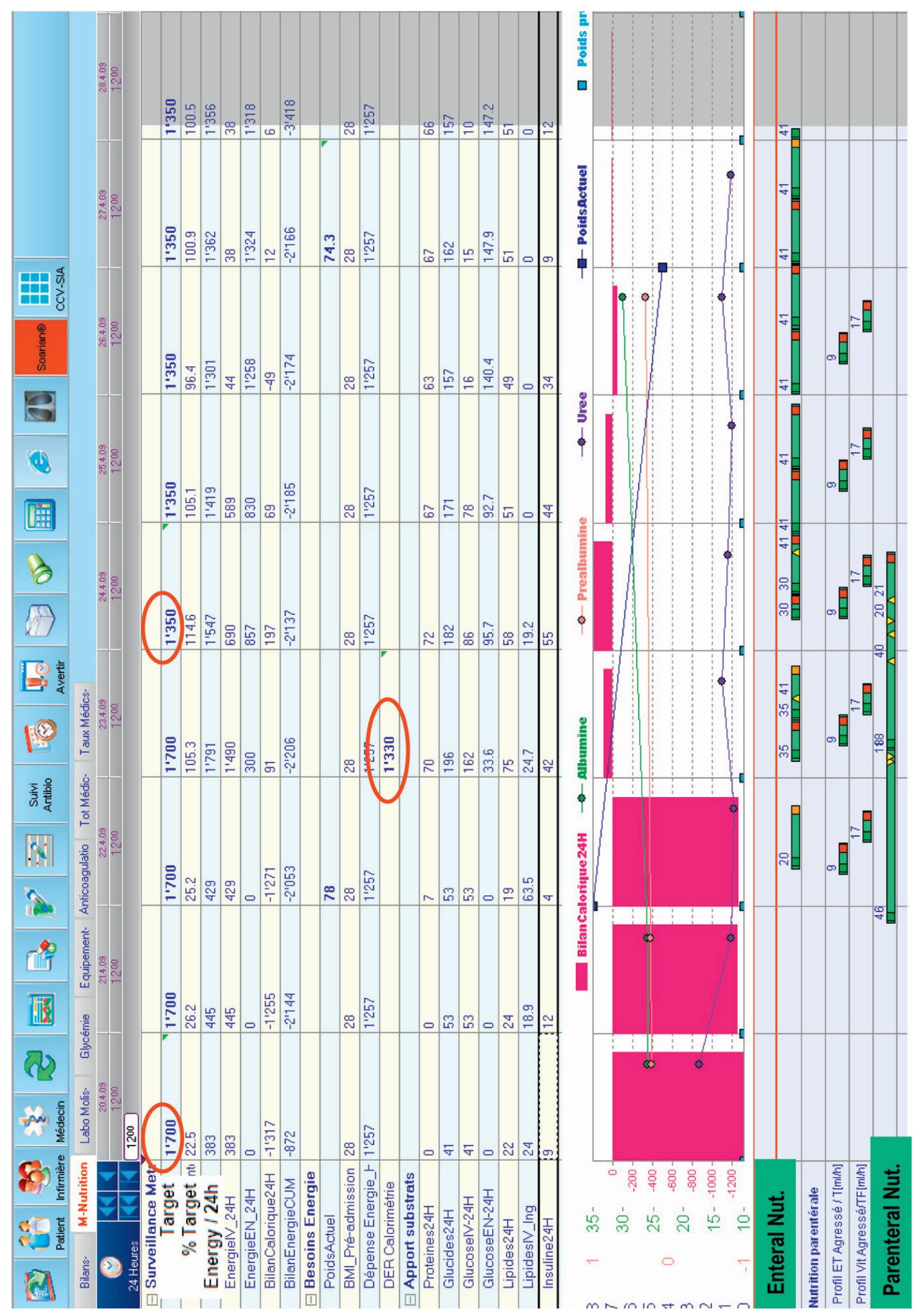

Figure 2. Monitoring screen customized to show nutritional information per $\mathbf{2 4}$ hours. The large red bars reflect negative balances (here present the 3 first days) or over-feeding: the closer the patient is to target, the thinner the bar. The tabular data provide information about energy delivery by intravenous and enteral routes, and about exact protein, glucose and fat delivery. The table also shows insulin requirements. 


\section{Timing and tools}

The answer to the wide persistence of malnutrition consists of a bundle of measures:

- Teaching about nutrition

- Application of guidelines

- Systematic target calculation with insertion in the medical order sheets

- Daily monitoring of nutrition delivery.

Teaching basic nutritional knowledge in medical schools is a big priority, and its absence in curricula is a worldwide problem [5,45]. Among the mnemotechnic tools, the "FAST HUG" strategy [46], where "F" stands for feeding, has only partially penetrated into the critical care milieu.

Guidelines provide standard targets for route, timing and energy targets. Timing is essential: Starting enteral nutrition within 24 hours in patients on mechanical ventilation is a very efficient way to reduce energy deficit [47]. Early enteral nutrition has a second advantage, which is to keep the gut working, particularly in the sickest patients. Prokinetics may help restore motility, and acupuncture may be even more effective than standard promotility medications [48]. Early feeding does not mean 'force feeding' though [49]; the sick gut is telling us something important, that we should listen too. Persistent gastric intolerance on day 3 automatically selects patients who will require supplemental parenteral nutrition.

In the absence of calorimetry, guideline targets should be applied, with a cautious initial $20-25 \mathrm{kcal} / \mathrm{kg} /$ day target increasing thereafter in the recovery phase. Importantly, when prescribing these targets one should integrate the existence of inadvertent non-nutritional energy intakes (see above). Monitoring energy balance to detect a growing energy debt is essential: This can be easily achieved with some computerized systems. Computer assisted nutritional support has been show to be more efficient in achieving energy targets $[25,50]$. Indeed, visualization of real-time energy delivery is an important tool to obtain a rapid response. Figure 2 shows the case of an elderly patient who was deemed 'nil per os' by the surgeon, with parenteral nutrition started on day 3 (some energy came from glucose $5 \%$ solution and propofol). The initial target was $1700 \mathrm{kcal}$ and was reset to $1350 \mathrm{kcal}$ on day 4 after calorimetry control. Discussion with the surgeons then enabled initiation of slow enteral nutrition on day 3, resulting in combined feeding for 3 days. Computerized information systems (CIS), also called Patient Data Management Systems (PDMS), are expensive, however, much more so than calorimeters. As an alternative, it is easy to create an Excel file (available worldwide) and to customize tables enabling rapid check of protein, glucose, lipid and calorie delivery per 24 hours: The precise $(\mathrm{ml})$ delivery of feeding solution and of drug solutions should be entered, including the sedative propofol (lipid) and other glucose containing solutions. Some applications for smartphones from the industry may also be helpful. Evidence is accumulating that the development of energy deficits $>-4000 \mathrm{kcal}$ should be prevented: Early enteral nutrition and the use of combined enteral and parenteral nutrition (in case of enteral nutrition failure) seem the best ways to achieve this target [51].

\section{Conclusion}

Nutrition is a medical therapy and basic rules need to be followed, such as respect of indications, contraindications and dose adaptation, timing of initiation, and monitoring. Timing has proven important in the prevention of malnutrition-related complications. Early enteral nutrition remains the best tool to prevent problems. We now know that combined feeding introduced around day 4 in those patients not achieving their targets is a second-line tool. Indeed, interventional trials that have respected these basic rules have achieved improved clinical outcomes. It is also important to check the target: Ventilators with integrated calorimeters would be a great help. Finally, as any therapy, under- and over-dosage must be avoided, which implies monitoring nutritional delivery in order to identify a growing energy gap or excess administration.

\section{Abbreviations}

ACCP, American College of Chest Physicians; BMI, body mass index; CIS, computerized information systems; EPaNIC, Early Parenteral Nutrition to supplement insufficient enteral nutrition in Intensive Care patients; ESPEN, European Society for Clinical Nutrition and Metabolism; ICU, intensive care unit; NO, nitric oxide; PDMS, Patient Data Management Systems; SPN, Supplemental Parenteral Nutrition; TICACOS, Tight CAlorie COntrol Study.

\section{Competing interests}

$C P$ received financial support as research grants \& consulting fees from Abbott, Baxter, B. Braun, Cosmed, Fresenius - Kabi, Nestle Medical Nutrition, Novartis, Nutricia - Numico, Pfizer, Solvay. MMB received financial support as research grants \& consulting fees from Laboratoires Aguettant, Baxter, B. Braun, Fresenius - Kabi and Nestlé Medical Nutrition.

\section{Author details}

'Service of Intensive Care Medicine \& Burns, CHUV, Lausanne, Switzerland. ${ }^{2}$ Clinical Nutrition, Geneva University Hospital, Geneva, Switzerland.

Published: 20 March 2012

\section{References}

1. Thibault R, Chikhi M, Clerc A, et al:: Assessment of food intake in hospitalised patients: a 10-year comparative study of a prospective hospital survey. Clin Nutr 2011, 30:289-296.

2. Alberda C, Gramlich L, Jones N, et al.: The relationship between nutritional intake and clinical outcomes in critically ill patients: results of an international multicenter observational study. Intensive Care Med 2009, 35:1728-1737

3. Rubinson L, Diette $G B$, Song X, Brower RG, Krishnan JA: Low caloric intake is associated with nosocomial bloodstream infections in patients in the medical intensive care unit. Crit Care Med 2004, 32:350-357.

4. Braga M, Gianotti L, Constantini E, et al:: Impact of enteral nutrition on intestinal bacterial translocation and mortality in burned mice. Clin Nutr 1994, 13:256-261. 
5. Möwe M, Bosaeus I, Rasmussen HH, et al:: Insufficient nutritional knowledge among health care workers? Clin Nutr 2008, 27:196-202.

6. Dissanaike S, Shelton M, Warner K, O'Keefe GE: The risk for bloodstream infections is associated with increased parenteral caloric intake in patients receiving parenteral nutrition. Crit Care 2007, 11:R114.

7. Krishnan JA, Parce PB, Martinez S, Diette GB, Brower RG: Caloric intake in medical ICU patients: consistency of care with guidelines and relationship to clinical outcomes. Chest 2003, 124:297-305.

8. McCowen KC, Friel C, Sternberg J, et al.: Hypocaloric total parenteral nutrition: effectiveness in prevention of hyperglycemia and infectious complications-a randomized clinical trial. Crit Care Med 2000, 28:3606-3611.

9. Berger $\mathrm{MM}$, Mechanick Jl: Continuing controversy in the intensive care unit: why tight glycemic control, nutrition support, and nutritional pharmacology are each necessary therapeutic considerations. Curr Opin Clin Nutr Metab Care 2010, 13:167-169.

10. Dvir $\mathrm{D}$, Cohen J, Singer P: Computerized energy balance and complications in critically ill patients: An observational study. Clin Nutr 2005, 25:37-44.

11. Villet $\mathrm{S}$, Chioléro RL, Bollmann MD, et al: Negative impact of hypocaloric feeding and energy balance on clinical outcome in ICU patients. Clin Nutr 2005, 24:502-509.

12. Weir JB: New methods for calculating metabolic rate with special reference to protein metabolism. J Physiol 1949, 109:1-9.

13. Weekes $E C$ : Controversies in the determination of energy requirements. Proc Nutr Soc 2007, 66:367-377.

14. Stapleton RD, Jones N, Heyland DK: Feeding critically ill patients: what is the optimal amount of energy? Crit Care Med 2007, 35:S535-S540

15. Plank LD, Hill GL: Energy balance in critical illness. Proc Nutr Soc 2003, 62:545-552.

16. Reid CL: Poor agreement between continuous measurements of energy expenditure and routinely used prediction equations in intensive care unit patients. Clin Nutr 2007, 26:649-657.

17. Koea JB, Wolfe RR, Shaw JH: Total energy expenditure during total parenteral nutrition: ambulatory patients at home versus patients with sepsis in surgical intensive care. Surgery 1995, 118:54-62.

18. Frankenfield DC, Coleman A, Alam S, Cooney RN: Analysis of estimation methods for resting metabolic rate in critically ill adults. JPEN J Parenter Enteral Nutr 2009, 33:27-36.

19. Walker RN, Heuberger RA: Predictive equations for energy needs for the critically ill. Respir Care 2009, 54:509-521.

20. Allard JP, Pichard C, Hoshino E, et al: Validation of a new formula for calculating energy requirements of burn patients. JPEN J Parenter Enteral Nutr 1990, 14:115-118

21. Faisy C, Guerot E, Diehl JL, Labrousse J, Fagon JY: Assessment of resting energy expenditure in mechanically ventilated patients. Am J Clin Nutr 2003, 78:241-249.

22. Grau T, Bonet A, Rubio M, et al: Liver dysfunction associated with artificial nutrition in critically ill patients. Crit Care 2007, 11:R10.

23. Biolo G, Ciocchi B, Stulle M, et al:: Calorie restriction accelerates the catabolism of lean body mass during 2 wk of bed rest. Am J Clin Nutr 2007 86:366-372

24. Biolo G, Agostini F, Simunic B, et al:: Positive energy balance is associated with accelerated muscle atrophy and increased erythrocyte glutathione turnover during $5 \mathrm{wk}$ of bed rest. Am J Clin Nutr 2008, 88:950-958.

25. Berger MM, Revelly JP, Wasserfallen JB, et al:: Impact of a computerized information system on quality of nutritional support in the ICU. Nutrition 2006, 22:221-229.

26. Ahrens $\mathrm{CL}$, Barletta JF, Kanji S, et al:: Effect of low-calorie parenteral nutrition on the incidence and severity of hyperglycemia in surgical patients: a randomized, controlled trial. Crit Care Med 2005, 33:2507-2512.

27. Fong $Y$, Marano MA, Braber A, et al:. Total parenteral nutrition and bowel rest modify the metabolic response to endotoxin in humans. Ann Surg 1989, 210:449-457.

28. Bartlett RH, Dechert RE, Mault JR, Ferguson SK, Kaiser AM, Erlandson EE: Measurement of metabolism in multiple organ failure. Surgery 1982, 92:771-779.

29. Villet $\mathrm{S}$, Chiolero RL, Bollmann MD, et al: Negative impact of hypocaloric feeding and energy balance on clinical outcome in ICU patients. Clin Nutr 2005, 24:502-509.
30. Doig GS, Simpson F, Finfer S, et al:: Effect of evidence-based feeding guidelines on mortality of critically ill adults: a cluster randomized controlled trial. JAMA 2008, 300:2731-2741.

31. Badjatia N, Fernandez L, Schlossberg MJ, et al:: Relationship between energy balance and complications after subarachnoid hemorrhage. JPEN $J$ Parenter Enteral Nutr 2010, 34:64-69.

32. Atkinson S, Sieffert E, Bihari D: A prospective, randomized, double-blind controlled clinical trial of enteral immunonutrition in the critically ill. Crit Care Med 1998, 26:1164-1172.

33. Faisy C, Lerolle N, Dachraoui F, et al:: Impact of energy deficit calculated by a predictive method on outcome in medical patients requiring prolonged acute mechanical ventilation. Br J Nutr 2009, 101:1079-1087.

34. Faisy C, Llerena M, Savalle M, Mainardi JL, Fagon JY: Early ICU energy deficit is a risk factor for Staphylococcus aureus ventilator-associated pneumonia. Chest 2011, 140:1254-1260.

35. Rimdeika R, Gudaviciene D, Adamonis K, Barauskas G, Pavalkis D, Endzinas Z: The effectiveness of caloric value of enteral nutrition in patients with major burns. Burns 2006, 32:83-86.

36. Weijs PJM, Stapel SN, de Groot SDW, et al:: Optimal protein and energy nutrition decreases mortality in mechanically ventilated, critically ill patients: a prospective observational cohort study. JPEN J Parenter Enteral Nutr, in press.

37. Awad S, Stephenson MC, Placidi E, et al: The effects of fasting and refeeding with a 'metabolic preconditioning' drink on substrate reserves and mononuclear cell mitochondrial function. Clin Nutr 2010, 29:538-544.

38. Wernerman J: Individualized ICU nutrition for a better outcome. Intensive Care Med 2011, 37:564-565.

39. Singer $P, A n b a r R$, Cohen J, et al:: The tight calorie control study (TICACOS): a prospective, randomized, controlled pilot study of nutritional support in critically ill patients. Intensive Care Med 2011, 37:601-609.

40. Casaer MP, Mesotten D, Hermans G, et al.: Early versus late parenteral nutrition in critically ill adults. N Eng/ J Med 2011, 365:506-517.

41. The Veterans Affairs Total Parenteral Nutrition Cooperative Study Group: Perioperative total parenteral nutrition in surgical patients. N Eng/ J Med 1991, 325:525-532.

42. Singer P, Berger MM, Van den Berghe G, et al:: ESPEN Guidelines on Parenteral Nutrition: intensive care. Clin Nutr 2009, 28:387-400.

43. Heidegger CP, Graf S, Thibault R, Darmon P, Berger MM, Pichard C: Supplemental parenteral nutrition (SPN) in intensive care unit (ICU) patients for optimal energy coverage: improved clinical outcome. Clin Nutr, in press.

44. Berger MM, Brancato V, Graf S, Heidegger CP, Darmon P, Pichard C: SPN study: supplemental aprenteral nutrition (PN) to reach energy target does not compromise glucose control. Clin Nutr, in press.

45. McClave SA, Mechanick Jl, Kushner RF, et al.: Compilation of recommendations from summit on increasing physician nutrition experts. JPEN J Parenter Enteral Nutr 2010, 34:1235-132S.

46. Vincent JL: Give your patient a fast hug (at least) once a day. Crit Care Med 2005, 33:1225-1229

47. Artinian V, Krayem H, DiGiovine B: Effects of early enteral feeding on the outcome of critically ill mechanically ventilated medical patients. Chest 2006, 129:960-967.

48. Pfab F, Winhard M, Nowak-Machen M, et al: Acupuncture in critically ill patients improves delayed gastric emptying: a randomized controlled trial. Anesth Analg 2011, 112:150-155.

49. Heyland DK, Cahill NE, Dhaliwal R, et al:: Enhanced protein-energy provision via the enteral route in critically ill patients: a single center feasibility trial of the PEP uP protocol. Crit Care 2010, 14:R78.

50. van Schijndel RJ, de Groot SD, Driessen RH, et al:: Computer-aided support improves early and adequate delivery of nutrients in the ICU. Neth J Med 2009, 67:388-393.

51. Heidegger CP, Romand JA, Treggiari MM, Pichard C: Is it now time to promote mixed enteral and parenteral nutrition for the critically ill patient? Intensive Care Med 2007, 33:963-969.

doi:10.1186/cc11229

Cite this article as: Berger MM, Pichard C: Best timing for energy provision during critical illness. Critical Care 2012, 16:215. 